\title{
Photosensitive Formulation for Additive Manufacturing-3D Printing
}

\author{
MARC JM ABADIE ${ }^{1,2 *}$, IULIAN MANOLE ${ }^{3}$, CATALIN FETECAU ${ }^{3}$ \\ ${ }^{1}$ Institute Charles Gerhardt Montpellier/AIME CNRS, University of Montpellier, France \\ 2"Petru Poni”'Institute of Macromolecular Chemistry, 41A Grigore Ghica Alley, 700487, Iasi, Romania \\ ${ }^{3}$ ReForm UDJG Interdisciplinary Research Platform, Center of Excellence Polymer Processing, "Dunarea de Jos" \\ University of Galați, 47 Domneasca Str., 800008, Galati, Romania
}

\begin{abstract}
UV curing is a photochemical process in which high-intensity ultraviolet light is used to instantly cure or "dry" coatings, inks, adhesives and thin film technology. It has been around as a coating for wood, paper and as a clear coating via photolithography process on printed circuit boards PCBs or integrated circuit boards ICBs for years. It is fast becoming one of the most popular techniques in the paint and coatings industry. Most of the formulation use multifunctional acrylate monomers or oligomers or a mixture of them that crosslink under exposure to UV/EB radiations in a free radical process. We briefly present the advantages of EB vs. UV. A new type of formulation based on multifuctional monomer of dicyclopentadiene epoxy derivative with additional diluent as coreactive solvent will be described and evaluated. This formulation differs from the acrylate one by the use of a cationic photoinitiator. The final product presents all the advantages of epoxy resins viz. better adherence, mechanical and thermal properties, compared to acrylate systems. Formulation has been optimized thanks to the differential scanning photocalorimetry DPC. This type of formulation is developed for additive digital manufacturing - 3D Printing (building layer by layer).
\end{abstract}

Keywords: Cationic photopolymerization 1, Epoxy 2, Kinetics, 3, 3D printing

\section{Introduction}

Photochemistry through Ultra Violet (UV) or Electron Beam (EB) radiation has been used for more than 40 years, specifically for coatings, adhesives, inks, and electronics in recent years [1]. Fast curing (usually less than 1 second), excellent film properties, essentially no volatile organic compounds (VOC) are the major benefits among many other advantages compared with conventional solvent-borne thermal curing process which is under increasing pressure from regulatory agencies to limit the amount of solvents emitted into the environment.

Curing process may be used for UV Curing of matrices limited to 200-500 $\mu \mathrm{m}$ thickness whereas EB curing is more devoted to polymer matrix fibrous composites (PMFCs) and have been developed due to the need for advanced materials required for aerospace and automotive applications with parts' thickness up to 10-20 cm, depending of the power of the EB. In recent years, major advances have been made in raw materials and equipment designs that make this unique technology available for more and new industrial applications.

In this paper we propose some formulation based on epoxies and di-vinyl ether, their respective photosensivity and photoreactivity to end-up to a system that could be used for additive manufacturing- 3D printing such as Digital Light Projector (DLP) or Stereolithograhy (SLA) 3D Printing [2]. Indeed, it is important to control, at room temperature, viscosity, photoreactivity and rapid curing (crosslinking rate) of the formulation in order to have a high-performance system. These parameters are essential to control for the optimization of the manufactured parts.

\footnotetext{
*email:marc.abadie@umontpellier.fr,marc@icmpp.ro
} 


\section{UV curing system}

\subsection{UV Basic}

The electromagnetic spectrum (Figure 1) [3] goes from low energy (radio waves) to high energy (electron beam). According to the Planck's equation $(\mathrm{E}=\mathrm{h} v=\mathrm{hc} / \lambda=1.197 \mathrm{~kJ} / \mathrm{mol})$ each radiation is associated to an energy. Among the UV radiation, only the Visible $[400 \mathrm{~nm}(299 \mathrm{~kJ} / \mathrm{mol}) \leq \lambda \geq 700 \mathrm{~nm}$ $(171 \mathrm{~kJ} / \mathrm{mol})]$ and UVA $[315 \mathrm{~nm}(380 \mathrm{~kJ} / \mathrm{mol}) \leq \lambda \geq 400 \mathrm{~nm}(299 \mathrm{~kJ} / \mathrm{mol})]$ need the presence of a Photoinitiator to be able to initiate a polymerization as the energy developed is not enough to break $\mathrm{C}$ C or C-O bonds $(\approx 350 \mathrm{~kJ} / \mathrm{mol})$, which is not the case for UVB $[280 \mathrm{~nm}(427 \mathrm{~kJ} / \mathrm{mol}) \leq \lambda \geq 315 \mathrm{~nm}$ $(380 \mathrm{~kJ} / \mathrm{mol})]$ and UVC $[100 \mathrm{~nm}(1,196 \mathrm{~kJ} / \mathrm{mol}) \leq \lambda \geq 280 \mathrm{~nm}(427 \mathrm{~kJ} / \mathrm{mol})]$ and a fortiori for lower wavelength as electron beam. In that later case there is no need of Photoinitiator.

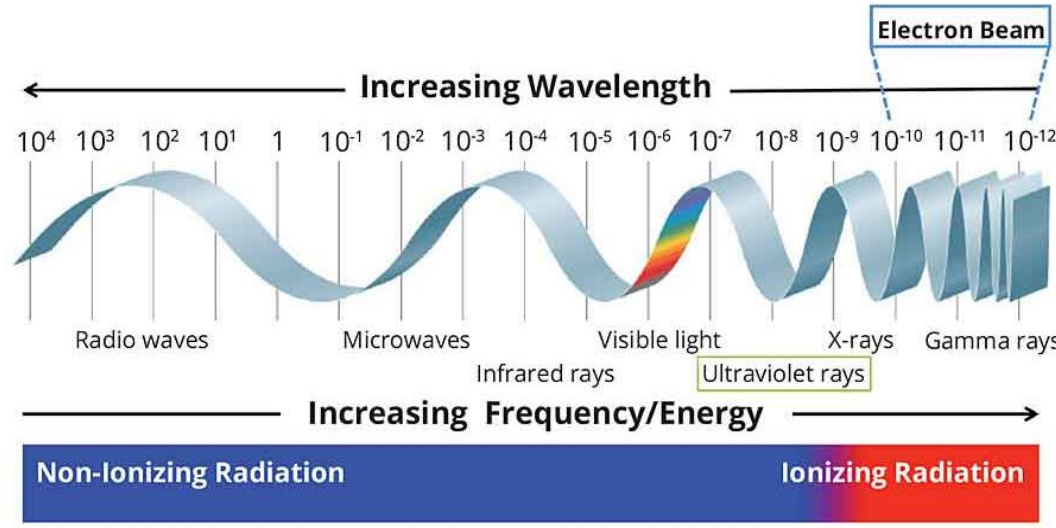

Figure 1. The electromagnetic spectrum

\subsection{Photosensitive formulation}

A Photosensitive formulation for UV curing contains Photoinitiator, Monomer / Multifunctional Oligomer and Additives. Photoinitiator for radical polymerization (acrylates, methacrylates) are classified as:

- Cleavage (type 1) - HAP (hydroxyacetophenone)ply.

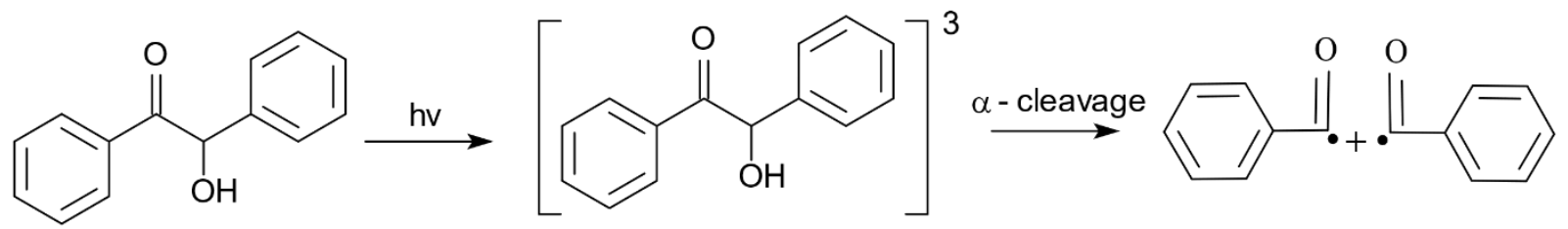

Scheme 1. HAP cleavage

As example of the photoinititors type I, the most used are :

- Irgacure ${ }^{\circledR} 651$ which decompose according

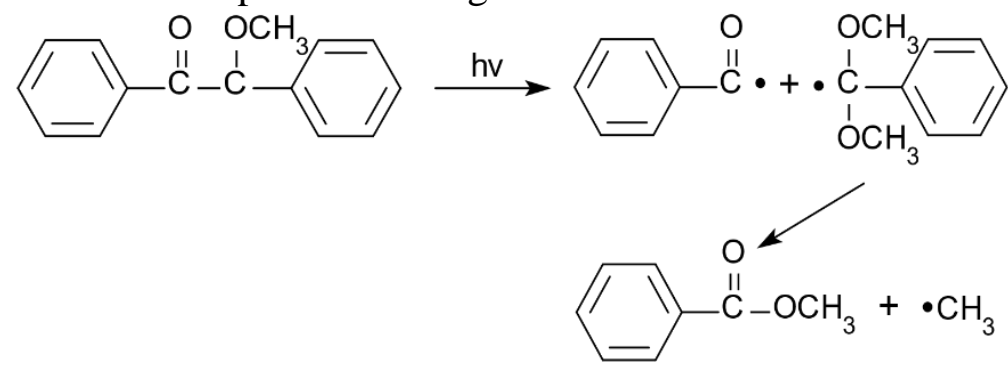

Scheme 2. Decomposes of Irgacure ${ }^{\circledR} 651$

giving two radicals : acetophenone and methyl radicals.

- Darocur ${ }^{\circledR} 1173$ : 
<smiles>CC(C)(O)C(=O)c1ccccc1</smiles>

Scheme 3. Darocur®1173 photoinitiator

It is one of the only photoinitiator that is liquid and decompose giving two radicals according :<smiles>CC(C)(O)C(=O)c1ccccc1</smiles>

Scheme 4. Decomposes of Darocur®1173

- Bis Acyl Phosphine Oxide (BAPO) :<smiles>CC1=CC2C3=CC=CC4c5cc(C)cc(C)c5C(=O)[PH](C)(C(=O)C2C(C)=C1)C34</smiles>

Scheme 5. BAPO photoinitiator

$\mathrm{H}$-abstraction type (type 2) initiators - $\mathrm{BP}+\mathrm{RNH} 2$ (benzophenone + amine)

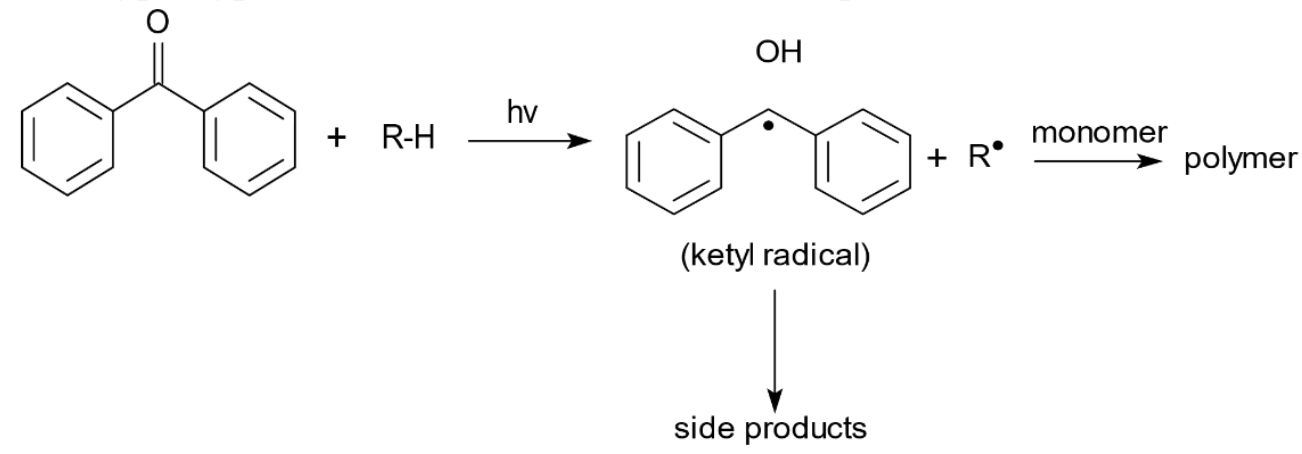

Scheme 6. Type 2 Benzophenone + amine polymerization process

Photoinitiators for cationic polymerization (epoxy and vinyl ether resins), upon exposure to UV light produce strong acid $[4,5]$ according the following scheme :

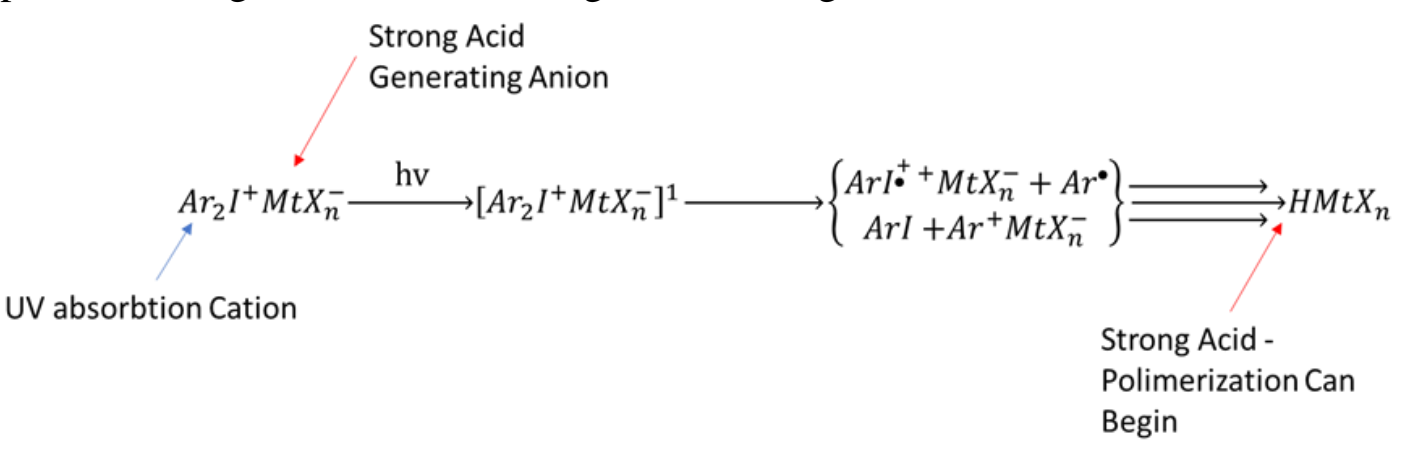

Scheme 7. UV polymerization of epoxy and vinyl ether resins

Epoxy polymerize by cationic process [6], initiated by a proton $\mathrm{H}+(\mathrm{HMtXn})$ according the following : 
<smiles>O=C(OCC1CCC2OC2CC1C(=O)OC1OC1C(F)(F)F)C1CCC2OC2C1</smiles>

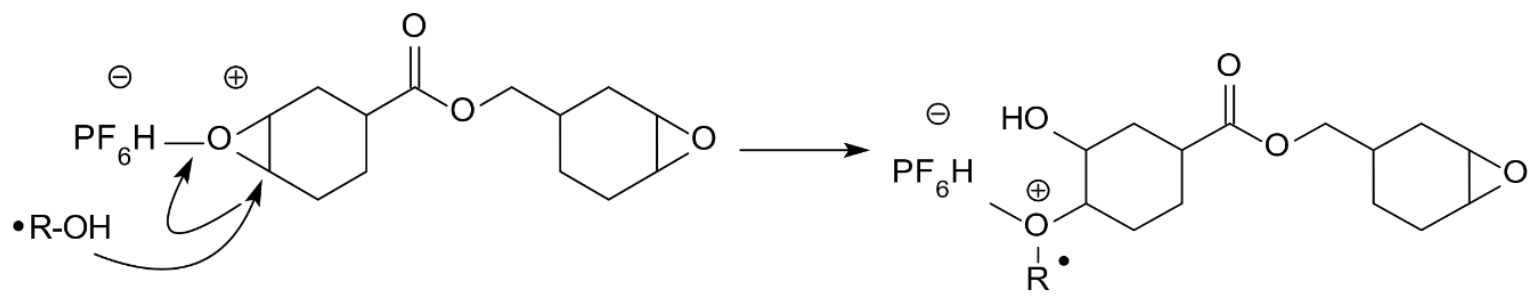<smiles>[R]OC1CCC(C(=O)OCC2CCC3OC3C2)CC1O</smiles><smiles>[R]O[C@H]1CC(C(=O)OCC2CCC(OCC)C(OCC)C2)CCC1OCCCC</smiles><smiles>CCC1CCC(O)C(C)C1</smiles>

Scheme 8. Epoxy polymerization process

It should be noted that, while radical polymerizations are sensitive to oxygen (chain peroxidation reaction leading to degradation of the polymer), this is not the case for cationic polymerizations. This remark is important because it does not require working in the absence of oxygen when using epoxy resins for $3 \mathrm{D}$ printing. Using additive with chlorinated anhydride may improves UV irradiation stability of epoxy resin [7].

According to the average functionality $\mathrm{f}$ of the monomer, for both radical or cationic mechanism, we do observe the formation of a linear polymer if $f=2$ or $3 \mathrm{D}$ network crosslinked structure if $f>2$. However, in most cases we are dealing with multifunctional monomers with $f_{a v}>2$. The photopolymerization process is represented Figure 2 .

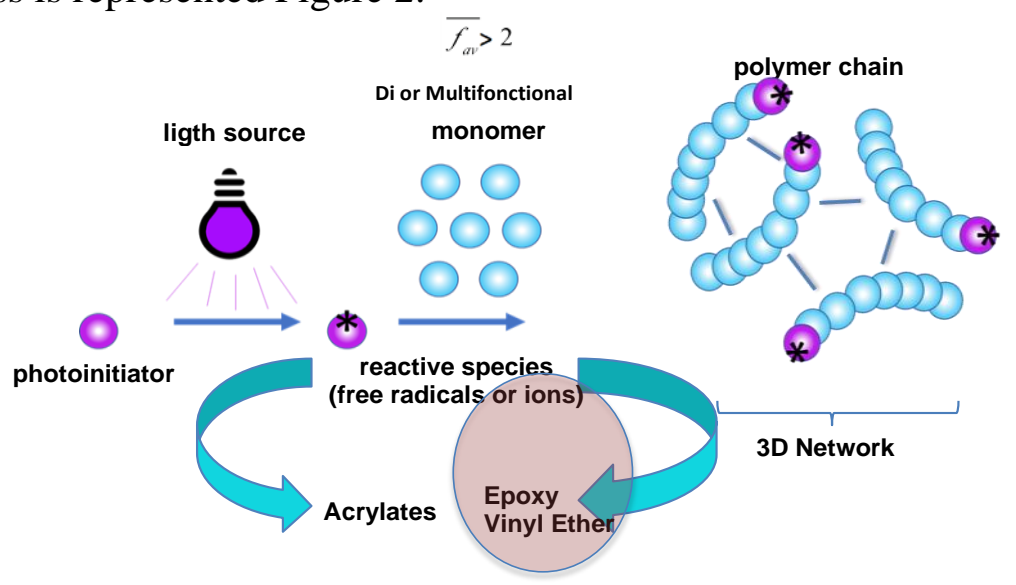

Figure 2. Scheme of Photo-polymerization 


\section{Materials and methods}

\subsection{Epoxy resins}

We have investigated formulation based on epoxy resins for the development of new organic matrices having strong mechanical properties-based 3D printing materials which can be cured without preliminary heating - under UV or e-beam curing and at room temperature, possessing increased thermal and mechanical properties and utilizable in corresponding applications.

Multifunctional epoxy polymers/monomers considered are based on dicyclopentadiene DCPD (Figure 3a), on naphthalene (Figure 3b \& 3c), on benzene (Figure 3d, 3e).

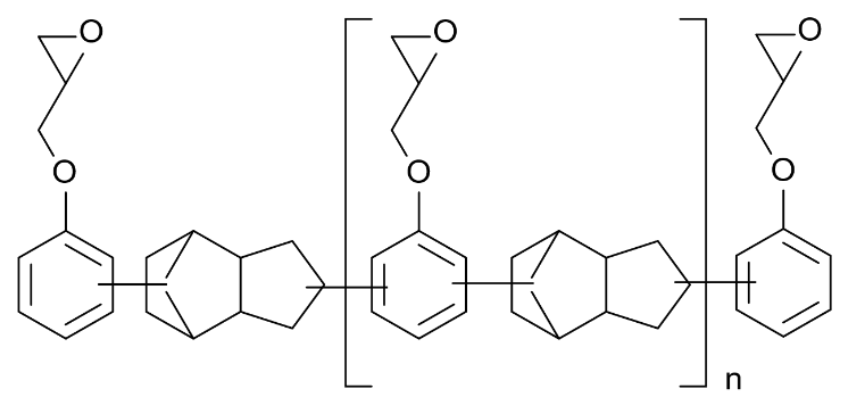

Figure 3a. Hepiclon ${ }^{\text {TMHP720 }}$<smiles>c1cc(OCC2CO2)c2ccc(OCC3CO3)cc2c1</smiles>

Figure 3b. Hepiclon ${ }^{\mathrm{TM}} \mathrm{HP} 4032$<smiles>c1cc2ccc(COC3CO3)c(Cc3c(OCC4CO4)ccc4ccc(OCC5CO5)cc34)c2cc1OCC1CO1</smiles>

Figure 3c. Hepiclon ${ }^{\mathrm{TM}} \mathrm{HP} 4710$<smiles>CC(CC1CO1)c1ccccc1OCC(O)C(C)Oc1ccccc1OCC1CO1</smiles>

Figure 3d. Hepiclon ${ }^{\mathrm{TM}} \mathrm{HP} 820$<smiles>c1cc(OCC2CO2)ccc1Cc1ccc(OCC2CO2)cc1</smiles>

Figure 3e. Epolam ${ }^{\circledR} 515$ 


\subsection{Co-monomersolvents}

As all the epoxy resins are solid except Epolam®515, Co-monomers used in all systems will play the role of solvent in view to get liquid formulation and also will participate to the cross-linking reaction once this reaction is initiated. As already mentioned for Epolam®515, another liquid epoxy such as Bis (3,4- epoxycyclohexylmethyl) adipate (Figure 4a) or 3,4 epoxycyclohexanecarboxylate have been used (Figure $4 b$ ).<smiles>O=C(CCCCC(=O)OCC1CCC2OC2C1)OCC1CCC2OC2C1</smiles>

Figure 4a. Epoxy adipate Cyracure®UVR6128.<smiles>O=C(OCC1CCC2OC2C1)C1CCC2OC2C1</smiles>

Figure 4b. Carboxylate Cyracure ${ }^{\circledR}$ UVR6105

We also have considered as co-monomer liquid vinyl ethers that polymerize by cationic mechanism (Figure 5).<smiles>C=COCC(C)(C)OC=C</smiles>

Figure 5. Rapid-Cure ${ }^{\circledR}$ DVE-3 Tri(ethylene glycol) di-vinyl ether

\subsection{Cationicphotoinitiator}

The photoinitiator (PI) Cyracure ${ }^{\circledR}$ UVI-6976 consist of a mixture 40/60 of dihexafluoroantimonate of S, S, S', S'-tetraphenylthiobis (4,1-phenyllene) disulfonium and hexafluoroantimonate of diphenyl (4-phenylthiophenyl) sulfonium (CAS no. 89452-32-9 and 71449-78-0) at 50\% by weight in propylene carbonate (Figure 6) [8].
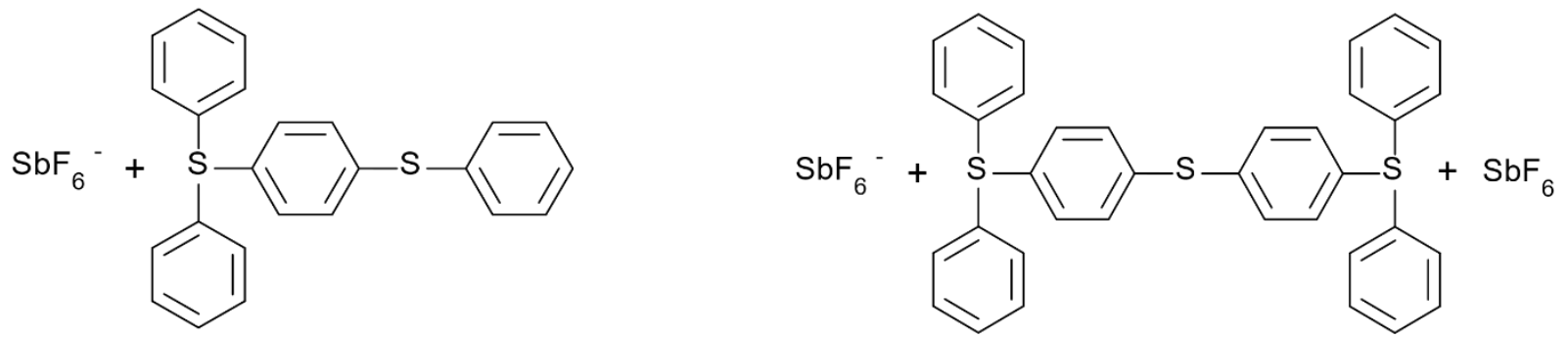

Figure 6. Cyracure ${ }^{\circledR} U V I 6976$

Note that recently a new cationic photo initiator has been proposed vs. iodonium and sulfonium salt containing tetrakis (perfluorotbutyloxy) aluminate anion Sulfonium/Iodonium Salt (Figure 7) [8].<smiles>[C+](c1ccccc1)c1ccccc1</smiles><smiles>[R]c1ccc([S+](c2ccc([R])cc2)c2ccc([R])cc2)cc1</smiles><smiles>FC(F)(F)C(F)(F)O[Ge](OC(F)(F)C(F)(F)F)(OC(F)(F)C(F)(F)C(F)(F)F)OC(C(F)(F)F)(C(F)(F)F)C(F)(F)F</smiles>

Figure 7. Tetrakis aluminate anion 
UV photopolymerization kinetics has been performed by Differential Scanning Photocalorimetry (DPC) monitoring the photopolymerization process which determine the photosensibility of any thin films (Figure 8) [9].

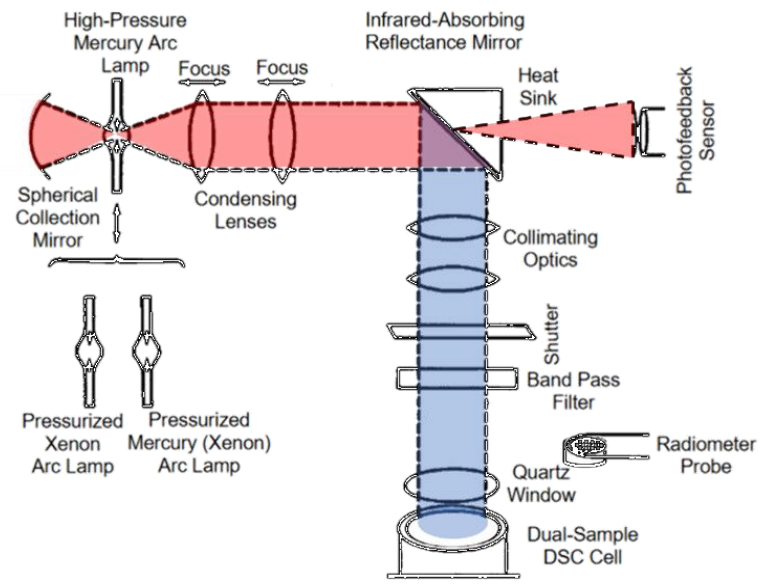

Figure 8. Schematic of DPC

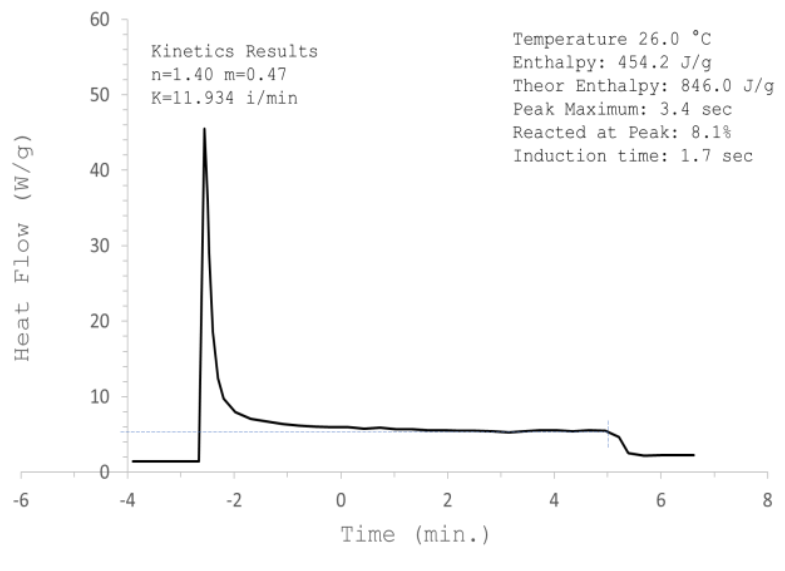

Figure 9. DPC photogram

Kinetics parameters of the epoxy systems have been studied using a TA Instrument \#912 based on DSC \#2920 Model Differential Photocalorimeter (DPC), equipped with a 200 W High pressure mercury lamp, giving an optical range from 285 to $440 \mathrm{~nm}$ with an intensity of 45 $\mathrm{mW} / \mathrm{cm}^{2}$ on the single DSC head (one sample and fully cured reference) [10].

The pan, filled fully cured under $20 \mathrm{~min}$ of the UV exposure sample of resin was used as a reference. The samples weighting $(2.0 \pm 0.2) \mathrm{mg}$ were placed in aluminum pans covered by PET film and subjected to $1 \mathrm{~min}$ of isothermal conditioning before and $5 \mathrm{~min}$ after of UV exposure.

Asanypolymerization reaction is an exothermic process, DPC allows to make kinetics according the DPC curve (Figure 9). Our kinetic results are based on Šesták \& Berggren's equation [9] (Table1).

Table 1. Kinetics: Rate coefficient of photocuring \& Activation Energy

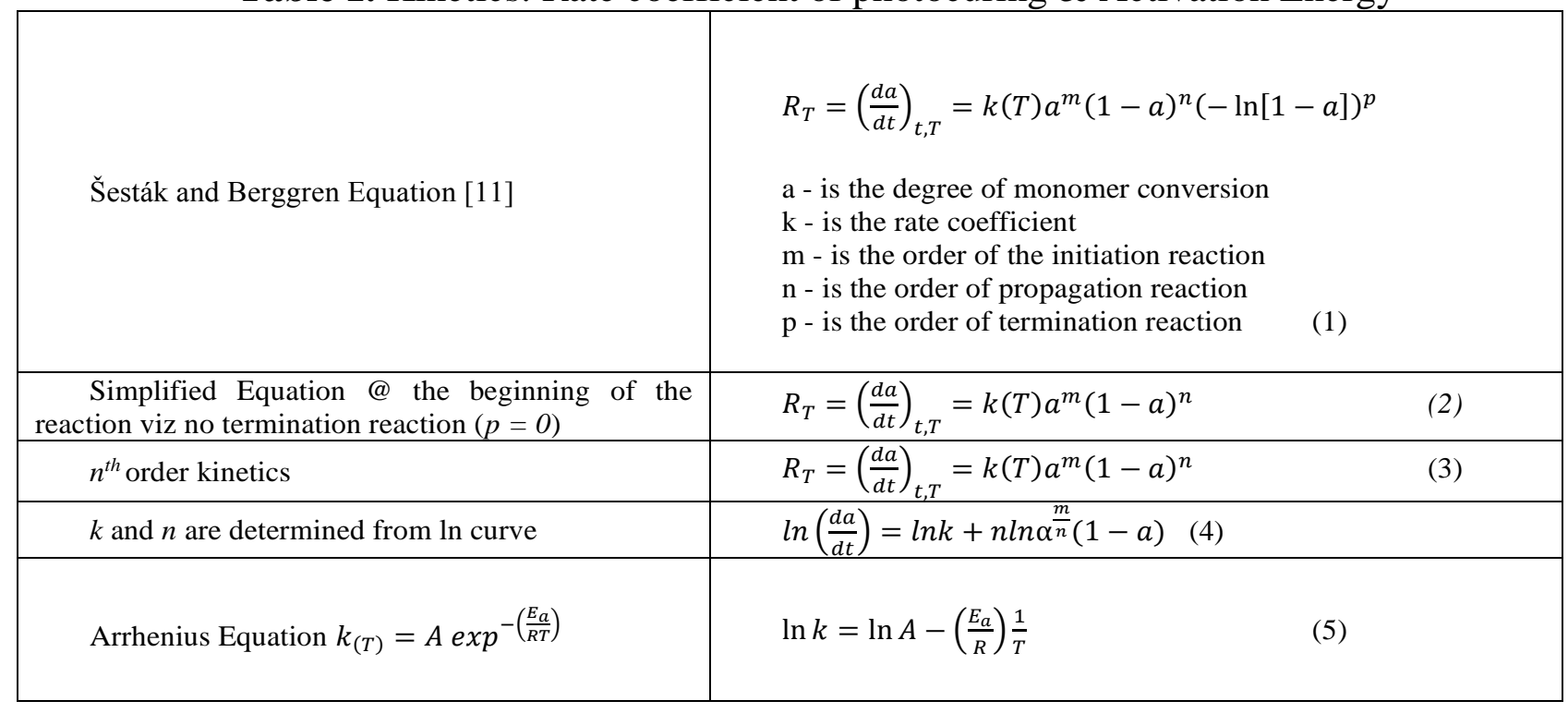

The reactions are conducted at different ratio monomer/co-monomer solvent to determine the rate coefficient $\mathrm{k}$ of the photopolymerization. Plotting $\mathrm{k}$ at different temperature allow to reach the activation energy $E_{a}$ of the considered system for each ratio [12]. 


\section{Results and discussions}

\subsection{Optimal conditions}

Both epoxy adipate (Figure 10) and epoxy carboxylate (Figure 11) have been studied using different concentrations of photoinitiator (PI) UVI-6976 in order to establish the optimum concentration of the PI to be added into the system. Concentrations of PI ranged from 0.5 to $5 \%$ by weight with reactivity being measured at a temperature of $30^{\circ} \mathrm{C}$. The monomer conversions reach a plateau at around $40-45 \%$ conversion for both oligomers with percentage conversion remaining constant for concentration between $3 \mathrm{wt} . \%$ and $5 \mathrm{wt}$ \% PI.

Addition of sulfonium salts even up to $5 \mathrm{wt} . \%$ appears not to produce any incremental increase in monomer conversion. This clearly establishes that the optimum photoinitiator concentration was 3 wt.\%. Following these results, therefore, all further experiments will be performed using the (PI) UVI6976 at a concentration of $3 \mathrm{wt} . \%$ with UV light intensity of $45 \mathrm{~mW} / \mathrm{cm}^{2}$

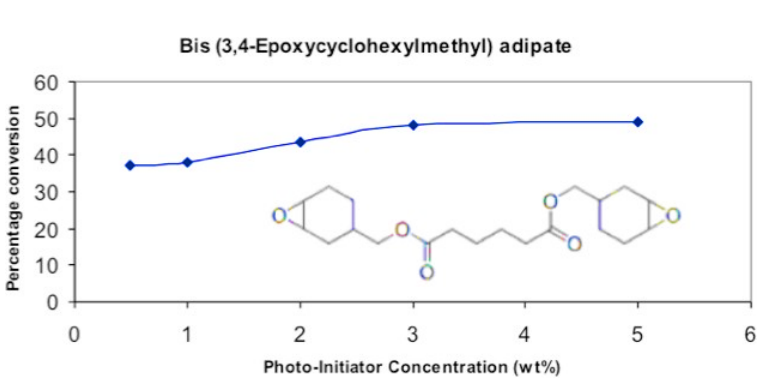

Figure 10. Epoxyadipate

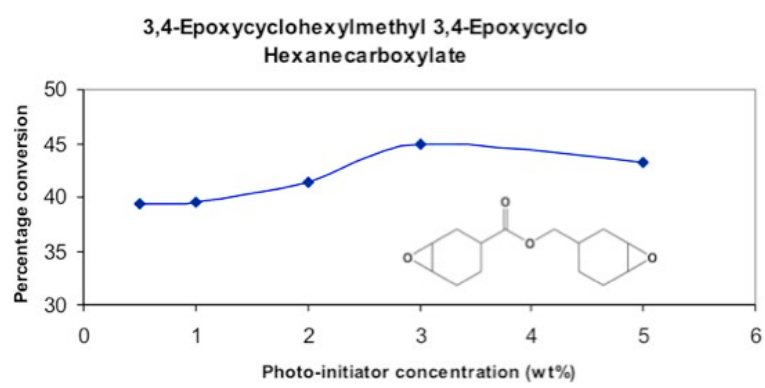

Figure 11. Epoxycarboxylate

\subsection{Co-monomer solvents}

The photoreactivity of co-monomer solvents have been established by DPC using Šesták \& Berggren's equation coupled to Arrhenius's parameters. As an example, we give the procedure used for the solvents epoxy adipate and carboxylate. Isothermal photo curing experiments were performed at five temperatures: $30,40,50,60$, and $70^{\circ} \mathrm{C}-$ DPC curves (Figures 12, 13), Conversion (Figures 14, 15), Rate coefficient (Table 2), Energy of activation (Table 3).

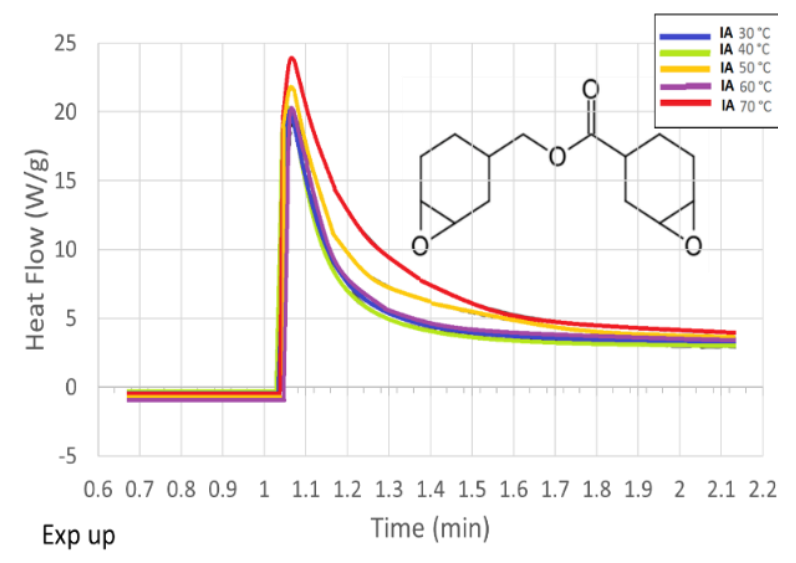

Figure 12. DPC curves ofepoxycarboxylate

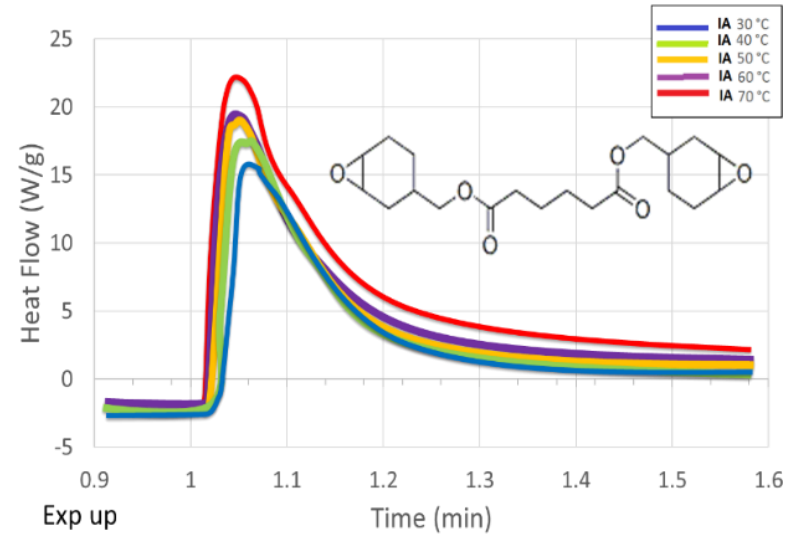

Figure 13. DPC curves of epoxyadipate 


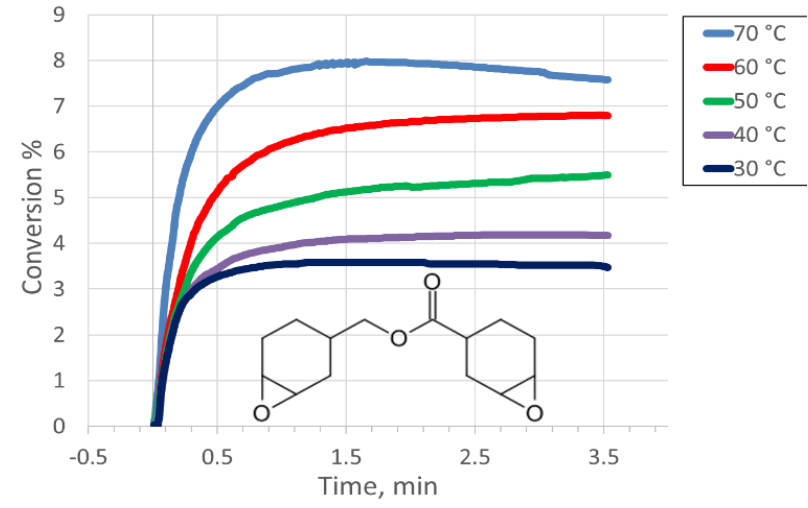

Figure 14. Degree of conversion ofepoxycarboxylate

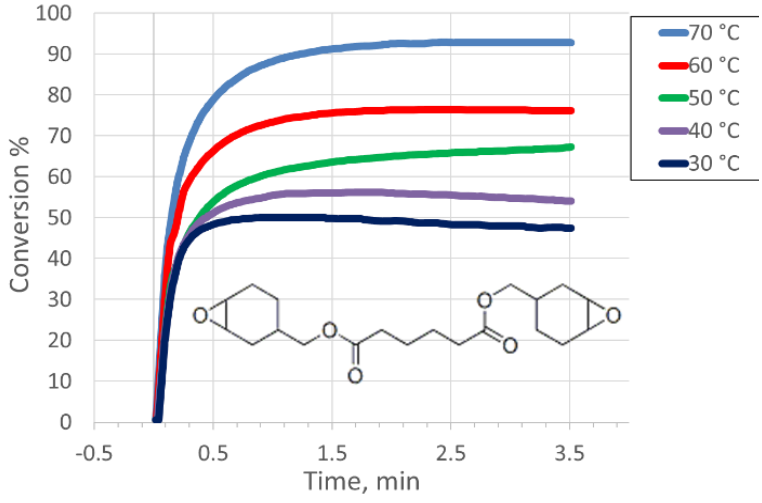

Figure 15. Degree of conversion of epoxyadipate

Values $\mathrm{k}$ (rate coefficient) and $\mathrm{n}$ can be determined from $\ln$ curve $-\ln (\mathrm{d} \alpha / \mathrm{dt})=\ln \mathrm{k}+\mathrm{n}$ $\ln \alpha \mathrm{m} / \mathrm{n}(1-\alpha)$ [Equation (4) and Figure 16] derivative from equation (2).

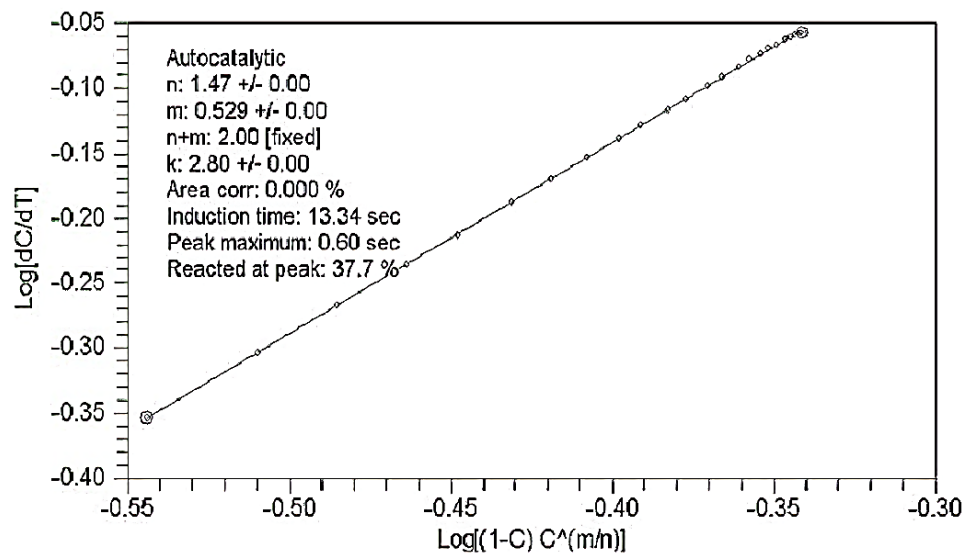

Figure 16. Evaluation of rate coefficient $\mathrm{k}$

The different kinetic values (Enthalpy of the polymerization $\mathrm{J} / \mathrm{g}$, Induction time $\mathrm{s}$, rate coefficient min-1) of epoxy carboxylate (Table 4) and epoxy adipate (Table 5) are calculated from the above results. Note that the induction time is the time for $1 \%$ conversion of the monomer i.e. lower is this value, faster is the reaction [13].

Table 4. Kinetic values for epoxy carboxylate

\begin{tabular}{|c|c|c|c|}
\hline $\mathrm{q}$ & $\begin{array}{c}\mathrm{DH} \\
(\mathrm{J} / \mathrm{g})\end{array}$ & $\begin{array}{c}\text { Induction } \\
\text { Time }(\mathrm{s})\end{array}$ & $\begin{array}{c}\mathrm{k} \\
\left(\mathrm{min}^{-1}\right)\end{array}$ \\
\hline 30 & $157 \pm 3$ & $2.18 \pm 0.02$ & $5.75 \pm 0.25$ \\
\hline 40 & $189 \pm 4$ & $1.77 \pm 0.02$ & $6.05 \pm 0.12$ \\
\hline 50 & $215 \pm 5$ & $1.57 \pm 0.01$ & $6.75 \pm 0.12$ \\
\hline 60 & $223 \pm 5$ & $1.41 \pm 0.01$ & $7.31 \pm 0.15$ \\
\hline 70 & $224 \pm 5$ & $1.35 \pm 0.01$ & $7.95 \pm 0.15$ \\
\hline
\end{tabular}

Table 5. Kinetic values for epoxy adipate

\begin{tabular}{|c|c|c|c|}
\hline $\begin{array}{c}\mathrm{q} \\
\left({ }^{\circ} \mathrm{C}\right)\end{array}$ & $\begin{array}{c}\mathrm{DH} \\
(\mathrm{J} / \mathrm{g})\end{array}$ & $\begin{array}{c}\text { Induction } \\
\text { Time }(\mathrm{s})\end{array}$ & $\begin{array}{c}\mathrm{k} \\
\left(\mathrm{min}^{-1}\right)\end{array}$ \\
\hline 30 & $120 \pm 2$ & $2.18 \pm 0.02$ & $16.81 \pm 0.25$ \\
\hline 40 & $133 \pm 4$ & $1.87 \pm 0.01$ & $17.40 \pm 0.25$ \\
\hline 50 & $159 \pm 5$ & $1.53 \pm 0.02$ & $18.42 \pm 0.25$ \\
\hline 60 & $190 \pm 3$ & $1.09 \pm 0.01$ & $19.78 \pm 0.25$ \\
\hline 70 & $224 \pm 5$ & $1.01 \pm 0.01$ & $20.43 \pm 0.25$ \\
\hline
\end{tabular}


From the Arrhenius plots (Figures 17, 18), activation energy can be calculated according the Arrhenius relationship: $\boldsymbol{k}_{(T)}=\boldsymbol{A} \exp ^{-\left(\frac{E_{a}}{R T}\right)}$

- $\mathrm{Ea}=(7.02 \pm 0.80) \mathrm{kJ}_{\mathrm{mol}} \mathrm{m}^{-1}$ for the epoxycarboxylate

- $\mathrm{Ea}=(4.03 \pm 0.20) \mathrm{kJ} \mathrm{mol}^{-1}$ for the epoxyadipate

3,4-epoxy cyclohexyl methyl-3,4-epoxycyclo hexane carboxylate

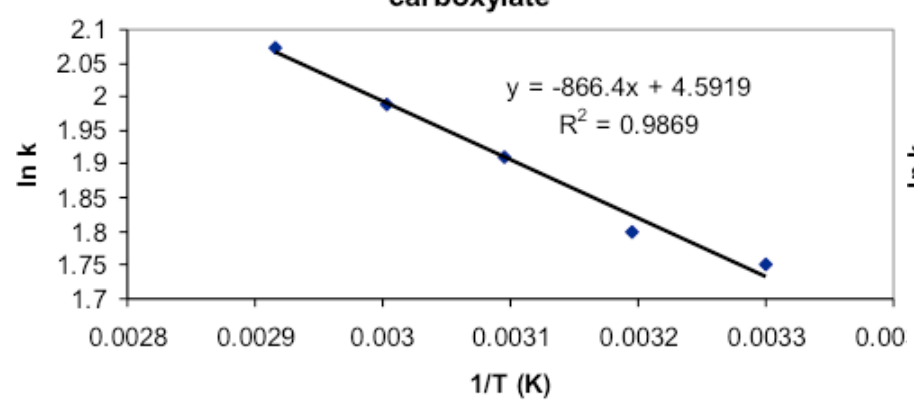

Figure 17. Arrhenius plot ofepoxycarboxylate
Bis (3,4-epoxycyclohexyl) adipate

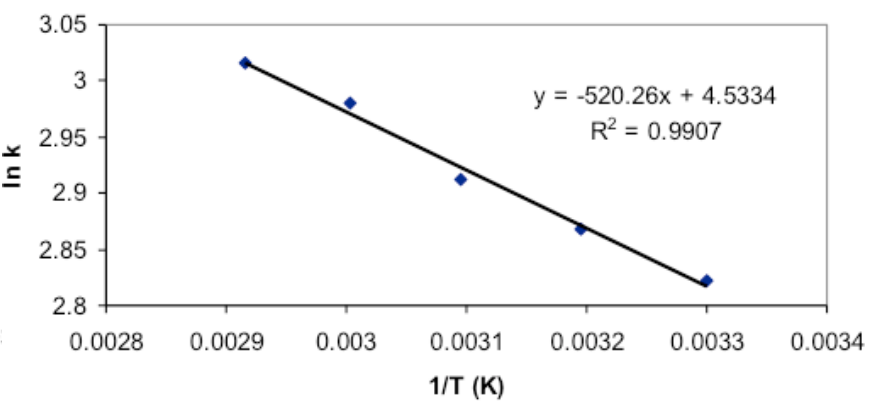

Figure 18. Arrhenius plot of epoxyadipate

It can be concluded that the polymerization reaction of the epoxy adipate proceeds almost two times faster than that of epoxy carboxylate, which corresponds to our expectation.

This could be explained by the additional carboxylate epoxy "space" group in the case of Bis- $(3,4-$ epoxycyclohexyl) adipate, which possessing a higher degree of liberty due to the presence of 2 carbonyl groups, 6 methylene groups and 2 oxygens, compared to carboxylate epoxy, has increased mobility, is more "flexible" and as a consequence is more reactive in photo induced polymerization.

Following the same rhetoric and methodology, we determined the activation energies of other comonomer solvents such as DVE-3 di-vinyl ether, Epolam® 515 which is a liquid monomer and therefore can be used as a co-monomer solvent. Overall results are given Table 6.

Table 6. Activation energy \& collision factor for 4 different co-monomer solvents

\begin{tabular}{|l|c|c|}
\hline Co-monomer solvent & $\begin{array}{c}\text { Activation Energy } \\
(\mathrm{kj} / \mathrm{mol})\end{array}$ & $\begin{array}{c}\text { Collision Factor } \\
\left(10^{3} \cdot \mathrm{min}^{-1}\right)\end{array}$ \\
\hline Epolam $^{\circledR} 515$ & $44.98 \pm 3.20$ & 50.76 \\
\hline Carboxylate & $7.02 \pm 0.80$ & 9.31 \\
\hline Adipate & $4.03 \pm 0.20$ & 9.87 \\
\hline DVE-3 Di-vinyl Ether & $3.60 \pm 0.42$ & 7.38 \\
\hline
\end{tabular}

From Table 6, it is obvious that the best solvent to be used is DVE-3 di-vinyl ether, the worst being Epolam ${ }^{\circledR} 515$ which is a resin epoxy based on methylene diphenol with $n=0$. The viscosity, that is strongly dependent of the chemical structure of the co-monomer solvent, plays a key role in the photoreactivity of the mixture polymer/co-monomer solvent.

Following these results, in our study on the optimization of the photoreactivity of polymer/comonomer solvent mixtures, we specifically focused on DVE-3 di-vinyl ether and epoxy adipate as interactive solvents.

\subsection{Polymer-monomer/co-monomersolvent}

We have analysed the following couple Polymer-Monomer/Co-monomer solvent:

- Hepiclon ${ }^{\mathrm{TM}}$ HP 720/DVE-3di-vinyl ether (Table7)

- Hepiclon ${ }^{\mathrm{TM}}$ HP 4710/ Epoxy adipate Cyracure ${ }^{\circledR}$ UVR 6128 (Table 8) 
- Hepiclon ${ }^{\mathrm{TM} H P 820 / E p o l a m}{ }^{\circledR 5} 515$ (Table 9) although Epolam ${ }^{\circledR 515}$ is the worst solvent for the photoreactivity according our precedent study at different ratio Polymer or Monomer/Co-monomer solvent.

Table 7. Hepiclon ${ }^{\mathrm{TM}}$ HP 720/DVE Di-vinyl ether

\begin{tabular}{|c|c|c|c|c|}
\hline HP 720/HVE & $0 / 100$ & $40 / 60$ & $60 / 40$ & $70 / 30$ \\
\hline Ea (kl.mol-1) & $3.6 \pm 0.4$ & $10.6 \pm 1.1$ & $22.8 \pm 1.8$ & $24.9 \pm 2.0$ \\
\hline A (103.min-1) & 7.47 & 89.7 & 6.9 .103 & 12.103. \\
\hline
\end{tabular}

Table 8. Hepiclon ${ }^{\mathrm{TM}}$ HP 4710/ Epoxy adipate

\begin{tabular}{|c|c|c|c|c|}
\hline HP 4710/Adipate & $0 / 100$ & $20 / 80$ & $30 / 70$ & $40 / 60$ \\
\hline $\mathrm{Ea}\left(\mathrm{kl}^{3} \mathrm{~mol}^{-1}\right)$ & $4.0 \pm 0.2$ & $10.26 \pm 1.70$ & $21.49 \pm 1.52$ & $29.4 \pm 2.1$ \\
\hline $\mathrm{A}\left(10^{3} \cdot \mathrm{min}^{-1}\right)$ & 9.86 & 6.75 & 426.4 & $4.10^{3}$ \\
\hline
\end{tabular}

Table 9. Hepiclon ${ }^{\text {TM }}$ HP 820/Epolam ${ }^{\circledR} 515$

\begin{tabular}{|c|c|c|c|c|}
\hline HP 820/Epolam & $0 / 100$ & $20 / 80$ & $40 / 60$ & $60 / 40$ \\
\hline $\mathrm{Ea}\left(\mathrm{kl}^{3} \mathrm{~mol}^{-1}\right)$ & $44.9 \pm 3.2$ & $51.1 \pm 4.5$ & $57.6 \pm 2.5$ & $65.1 \pm 3.1$ \\
\hline $\mathrm{A}\left(10^{3} \cdot \mathrm{min}^{-1}\right)$ & 50.8 & 59.3 & 67.9 & 78.4 \\
\hline
\end{tabular}

Comparing the results of Tables 7, 8, we can see that for an activation energy Ea $\approx 10 \mathrm{~kJ} / \mathrm{mol}$ we have 40 wt.\% Hepiclon ${ }^{\mathrm{TM}}$ HP 720 Polymer/60 wt.\% DVE-3 for only 20 wt.\% Hepiclon ${ }^{\mathrm{TM}}$ HP 4710 monomer/80 wt.\% adipate or for the same ratio 40/60 the system HP 720/DVE-3 is three times mor reactive than HP 4710/adipate. This difference shows the decisive influence of the solvent, in other words confirms that DVE-3di-vinyl ether has a better influence on the photoreactivity of the system under consideration than epoxy adipate.

As expected, the use of Epolam ${ }^{\circledR} 515$ (Table 9) leads to high activation energies, confirming the results of the Table 6.

\section{Conclusions}

We studied the photoreactivity of different co-monomer solvents - multi-epoxy or - vinyl-ethers (sensitive to a cationic polymerization mechanism) by considering their activation energy $\mathrm{E}_{\mathrm{a}}$. This study was continued by analysing different formulations based on these polymers or multifunctional epoxy monomers.

As follows from the results, the co-monomer solvent plays an essential role in the photoreactivity of a formulation, particularly the DVE-3di-vinyl ether because of its low viscosity, but also due to its chemical structure ( $3 \mathrm{O}$ oxygen and $6 \mathrm{CH} 2$ methylene groups) that makes the molecule more flexible and therefore more reactive than adipate and others.

Such formulation ensures reliable performance characteristics of the cured coatings with various practical applications for 3D printing.

Acknowlegments: This article was presented at Polymer Processing in Engineering Conference - PPE 2019, 7- 9 October 2019, Galati - Romania.

\section{References}

1.ABADIE M.J.M., VOYTEKUNAS V., Eurasian ChemTech Journal, 6, 2004, p.67-77.

2.REDWOOD B., SCHOFFER F., GARRET B., The 3D Printing Handbook Technologies Design and Applications, Hardcover Brand, ISBN: 9082748509, 2017, 347 Pages.

3.ANTHONY C., BNP Media, PCI Magazine, Electron Beam Laboratory Systems, October 1, 2015,https://www.pcimag.com/articles/101173-electron-beam-laboratory-systems 
4.SANGERMANO M., ROPPOLO I., CHIAPPONE A., Polymers, 10, 2018,p.136. doi:10.3390/polym 10020136

5.MICHAUDEL Q., KOTTISCH V., FORS B.P., Chem. Int. Ed., 56, 2017, p.9670-9679,doi:10.1002/ anie. 201701425

6.LALEVEE J., MOCKBEL H., FOUASSIER JP., Molecules, 20, 2015, p. 7201-7221. doi:10.3390/ molecules20047201

7.PETREU O., CIOBANU C., HAMCIUC C., VLAD-BUBULAC T., ROSU D., Mater Plast, 44, (2), 2007, http://www.revmaterialeplastice.ro/pdf/MP2_2007_3.pdf

8.GOTRO J., UV, Polymer Innovation Blog, February 8, 2016, https://polymerinnovationblog.com/uvcuring-part-five-cationic-photopolymerization/

9.APPELT B.K., ABADIE M.J.M., Polym. Eng. \& Sci., 25, 15, 1985, p.931-933.

10.ABADIE M.J.M., APPELT B.K., Bull. Soc. Chim. Fr., 1, 1988, p.20-24.

11.SESTÁK J., BERGGREN G., Thermochimica Acta, 3, 1972, p.1-12.

12.APPELT B.K., ABADIE M.J.M., Polymer Eng. Sci, 27, 1987, p.25

13.ABADIE M.J.M., APPELT B.K., Adv. Dent. Comp., 5, 1, 1989, p.6-9.

$\overline{\text { Manuscript received: 20. 12. } 2019}$ 